\title{
EXTENSIVE CALCIFICATION OF THE MITRAL VALVE ANULUS: PATHOLOGY AND SURGICAL MANAGEMENT
}

Alain F. Carpentier, MD, PhD

Michel Pellerin, $\mathrm{MD}^{*}{ }^{\&}$

Jean-François Fuzellier, $\mathrm{MD}^{\S}$

John Y. M. Relland, MD $^{\S}$
Extensive calcification of the mitral valve anulus is a pathologic entity frequently associated with degenerative valvular disease. The calcification process remains localized to the anulus in $77 \%$ of the cases. It may extend, however, to the underlying myocardium. Whenever an operation is necessary for an associated valve insufficiency, the question arises whether it is preferable to repair or to replace the valve and how to manage the calcification. In the first part of this paper the pathology of this disease is studied, and in the discussion a mechanism is proposed to explain the development of the process of calcification. In the second part, a new operation is described, which comprises the temporary detachment of the leaflets, en bloc resection of the calcium deposit, annular reconstruction, and valve repair. For patients in whom the calcification extends to the myocardium a "sliding atrioplasty" of the left atrium is described, which allows the area of exposed muscular fibers to be covered. Between 1986 and 1994, among 68 patients with extensive calcification of the anulus and severe mitral valve insufficiency, 67 benefited from these repair techniques. Ages ranged from 18 to 82 years (mean 62 years). Thirty-two patients had a billowing mitral valve (Barlow), 27 a fibroelastic deficiency, and two Marfan's disease. The calcification involved more than one third of the anulus in $88 \%$ of the patients, the posterior anulus in $10.5 \%$, and the whole anulus in $1.5 \%$. The calcification process extended to the myocardial wall in $12 \%$ of the patients and to the papillary muscles in $4.5 \%$. In the group of 67 valve repairs, there were two hospital deaths $(\mathbf{2 . 9 \%})$, no instances of anulus dehiscence, and no early reoperations. The follow-up period extended from 4 months to 8 years (mean 3 years 8 months). There were two late deaths, 2 and 17 months after the operation, for an actuarial survival of $93 \%$ at 7
$\mathrm{E}^{\mathrm{x}}$ tensive calcification of the mitral valve anulus is a pathologic entity, either isolated or associated with mitral valve insufficiency. In its most characteristic

From the Department of Cardiovascular Surgery and Organ Transplantation, Hôpital Broussais, Paris, France.

Read at the Seventy-fifth Annual Meeting of The American Association for Thoracic Surgery, Boston, Mass., April 23-26, 1995.

Received for publication May 30, 1995; revisions requested June 22, 1995; revisions received Nov. 13, 1995; accepted for publication Nov. 18, 1995.

Address for reprints: Alain F. Carpentier, MD, PhD, Chairman, Cardiovascular Surgery Department, Hôpital Broussais, 96, rue Didot, 75014 Paris.

*Research Fellow from the Heart and Stroke Foundation of Canada, 1993-1995.

${ }^{s}$ By invitation.

J Thorac Cardiovasc Surg 1996;111;718-30

Copyright (C) 1996 by Mosby-Year Book, Inc.

$0022-5223 / 96 \$ 5.00+0 \quad \mathbf{1 2 / 6 / 7 0 7 9 3}$ configuration, it forms a semilunar deposit of calcium within the anulus fibrosus, with limited extension to the leaflet tissue. This process differs from the calcifications seen in rheumatic valvular diseases, which usually involve the commissures and the leaflet tissue with only late extension to the anulus. Extensive calcification of the mitral valve anulus is encountered either in elderly persons with a fibroelastic deficiency of the mitral valve ${ }^{1}$ or in younger adults with a billowing mitral valve (Barlow's disease) or Marfan's disease. Whenever severe mitral valve insufficiency is associated with this process, a surgical operation is necessary, raising the questions of how best to manage the calcification and whether to repair or to replace the mitral valve.

\section{Patients and methods}

From July 1986 to March 1995, 68 patients with extensive calcification of the mitral anulus and severe valve 
years. Late reoperation ( 6 to 62 months) was necessary in four patients $(6.4 \%)$ for residual mitral valve incompetence $(n=2)$, hemolysis $(n=1)$, or endocarditis $(n=1)$. In one of these patients a new repair was possible, whereas the three other patients required a valve replacement. All patients but one survived the reoperation. Actuarial freedom from reoperation was $87 \%$ at 7 years. All 60 patients with valve repair were reviewed for this study by clinical examination and echocardiography. All but one were in functional class I or II. There was no incompetence or trivial residual mitral valve incompetence in 55 patients and moderate incompetence in five. Two thromboembolic events have been recorded for a linearized rate of $1 \% / \mathrm{pt}$-yr. This study shows that complete anulus decalcification and valve repair can be done safely in patients with mitral valve insufficiency and extensive calcification of the anulus, even when the calcification process deeply involves the myocardium. It also demonstrates that an initially good result remained stable up to 7 years. (J ThORaC Cardiovasc SuRg 1996;111: 718-30)

insufficiency were operated on in our institution. The group comprised 35 men and 33 women aged 18 to 82 years (mean $62 \pm 13$ years). Age varied according to the cause of valvular disease. In the group of patients with fibroelastic deficiency, age varied from 18 to 62 years with a mean of 56 years; in the Barlow or Marfan group, age varied from 62 to 82 with a mean of 67 years.

Preoperative patient characteristics are listed in $\mathrm{Ta}$ ble I. All patients had a preoperative echocardiogram: 60 had grade 3 to $4+$ mitral valve insufficiency and the remaining eight had grade $2+$ mitral valve insufficiency. In the latter group, the operation was indicated because of impaired functional capacity resulting from atrial fibrillation. The mitral valve insufficiency was classified into three functional types according to the classification of Carpentier and associates ${ }^{1}$ (Table II). The mean left ventricular end-diastolic and end-systolic diameters were, respectively, $63 \pm 6 \mathrm{~mm}$ and $40 \pm 6 \mathrm{~mm}$ with a mean shortening fraction of $37 \% \pm 10 \%$.

Pathology. The extension of calcification was assessed by roentgenograms, echocardiograms, and intraoperative examination.

Circumferentially, the calcification process involved at least one third of the posterior anulus in $88 \%$ of the cases and the whole posterior anulus in $10 \%$; it extended to the attachment of the anterior leaflet in $1.5 \%$ (Fig. 1). Limited calcifications involving less than one third of the posterior anulus were excluded from this series.

Vertically, the calcification process was restricted to the anulus itself in $77 \%$ of the cases. It extended to the leaflet tissue in $6 \%$, the ventricular myocardium in $12 \%$, and the anterior papillary muscle in $4.5 \%$ (Fig. 2). Of note is the fact that the calcium formation was encapsulated into a fibrous sheath quite distinct from the surrounding tissues. Fibrous encapsulation, however, was not well delineated in the areas of myocardial infiltration by the calcium process.

Beyond the limits of the calcification, in all the cases but four, the remaining anulus fibrosus displayed many fissures and zones of dehiscence exposing the underlying annular tissue to the blood components. These defects were filled with lipoid substances, protein deposits, platelets, and red cell aggregates. The closer to the calcified process these deposits were, the more organized they were, with spots of early mineralization. In front of these areas, as well as in areas of mature calcification, the leaflet tissue was dysplastic and enlarged, either billowing or prolapsed.

The disease responsible for the mitral valve insuffciency was assessed by clinical history, gross examination of the valve, and histologic examination. It could be recognized in 62 patients: Barlow's disease in $32(47.7 \%)$, fibroelastic deficiency in $27(40.3 \%)$, Marfan's disease in two $(3 \%)$, and obstructive cardiomyopathy in one patient $(1.5 \%)$. In five patients, the gross appearance and histologic features of the leaflet tissue were normal and annular calcification seemed to be the cause of the mitral valve insufficiency.

The lesions responsible for the valve dysfunction are listed in Table III.

These pathologic findings have at least two important surgical implications: (1) The calcium formation can be easily removed en bloc provided that the sheath enveloping the calcium is preserved; (2) the process of calcification can be stopped provided that all calcium or precalcium formations are removed and stress on leaflets is reduced.

Surgical technique. The surgical technique comprises two steps: (1) en bloc decalcification and reconstruction of the anulus and (2) valve repair or replacement. Valve repair is the preferred method. It was possible in 67 of the 68 cases in this series.

Anulus decalcification and reconstruction. The operation is done with the aid of cardiopulmonary bypass and moderate hypothermia $\left(25^{\circ} \mathrm{C}\right)$. Once the heart fibrillates, the mitral valve is approached through the left atrial roof after wide dissection of the atrioventricular (AV) groove. The valve is analyzed before cardioplegia is instituted, because the fibrillating heart still maintains adequate myocardial tone. This avoids false leaflet prolapse, which would be produced by cardioplegia-induced heart relax- 


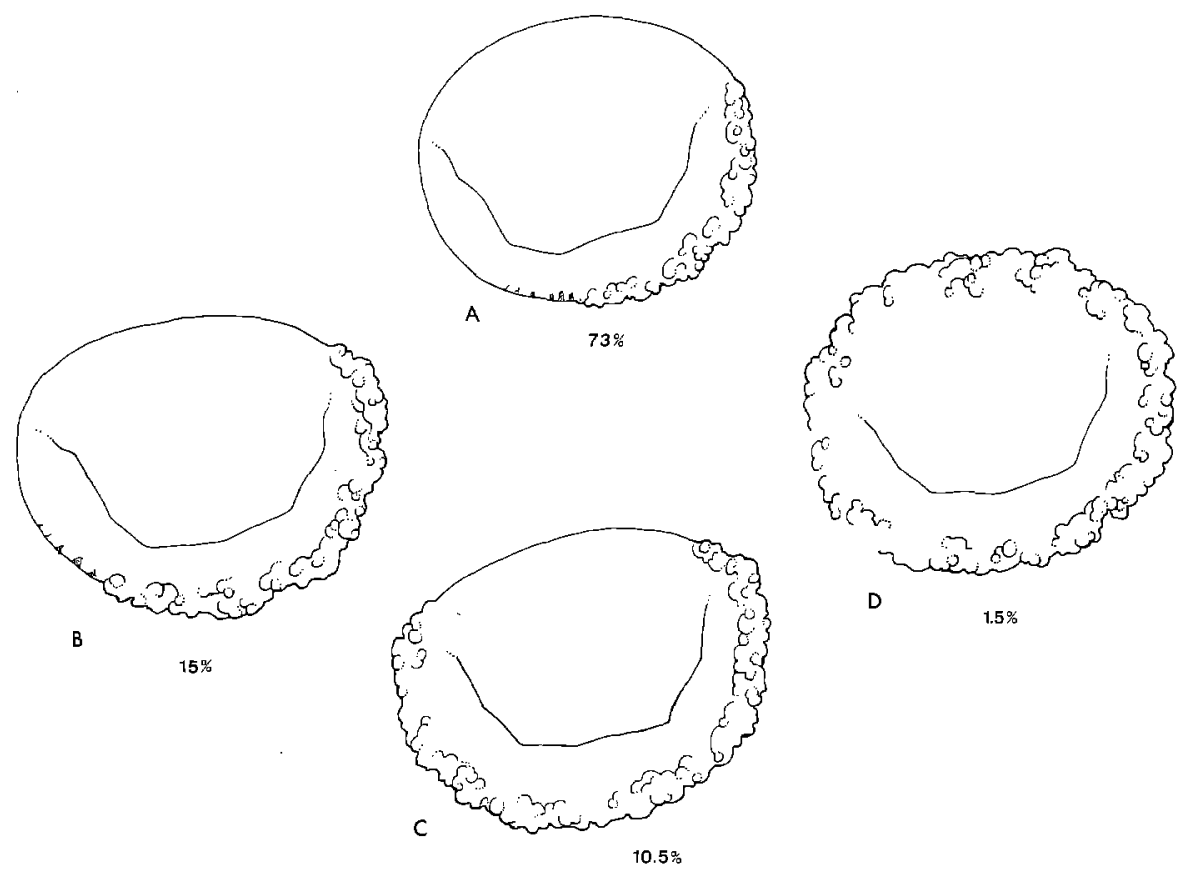

Fig. 1. Anulus extension of the calcification process.

Table I. Preoperative patient characteristics

$\begin{array}{lc}\text { No. of patients } & 68 \\ \text { Male } & 35(51 \%) \\ \text { Female } & 33(49 \%) \\ \text { Age (yr) } & 62 \\ \text { Mean } & 18-82 \\ \text { Range } & \\ \text { NYHA class }(\%) & 49 \\ \text { I-II } & 51 \\ \text { III-IV } & 69 \\ \text { Sinus rhythm (\%) }\end{array}$

NYHA, New York Heart Association.

ation. The valve must be analyzed in a systematic manner with the use of the Carpentier functional classification and segmental analysis. ${ }^{1-3}$ This allows the optimal techniques of valve reconstruction to be chosen. The ascending aorta is then clamped and cold hyperkalemic blood cardioplegic solution is infused antegradely into the aortic root. Decalcification is begun by using a knife to incise the atrial endothelium around the borders of the calcified bar (Fig. 3). Then the base of the mural leaflet is incised at the edge of the calcium bloc and retracted. This provides extensive exposure of the calcified anulus. Keeping the edge of the dissecting knife blade against the calcium allows the attachment of the anulus to be sharply removed from the AV tissue. This dissection is facilitated by the fact that the calcium formation is encapsulated within a fibrous sheath, which allows an en bloc resection without calcium fragmentation (Fig. 4). The dissection is most easily
Table II. Carpentier functional classification

\begin{tabular}{lrc} 
Type I: Normal leaflet motion & & $2(3 \%)$ \\
Type II: Leaflet prolapse & & $63(92.6 \%)$ \\
Anterior leaflet (II A) & $1.5 \%$ & \\
Posterior leaflet (II P) & $48.5 \%$ & \\
II A + II P & $38 \%$ & \\
II A + III P & $4.5 \%$ & \\
Type III: Restricted leaflet motion & & $3(4.4 \%)$ \\
\hline
\end{tabular}

performed by developing a plane from one extremity of the calcium bar and then dissecting under the entire length of the block until it is removed. At this point one can easily identify the AV fat circumscribed by the atrial edge superiorly and the ventricle inferiorly. This fat contains and protects the circumflex artery and vein. Depending on the extension of the calcium process, two different techniques of anulus reconstruction are used.

ANULUS RECONSTRUCTION IN ANULUS CALCIFICATION. In most instances, the calcification process is limited to the anulus itself, and the en bloc decalcification leaves two edges of fibrous tissue delimiting the atrium superiorly and the ventricle inferiorly. The AV junction is reconstructed by a series of figure-of-eight 2-0 braided sutures placed into the atrial and ventricular edges (Fig. 5). These sutures are then brought out on the atrial side. The ventricular bites of these sutures should involve only one third of the thickness of the myocardial wall and be as wide as possible, taking advantage of any fibrous tissue present on the surface of the endothelium. No Teflon pledgets should be used, so that compression of the 

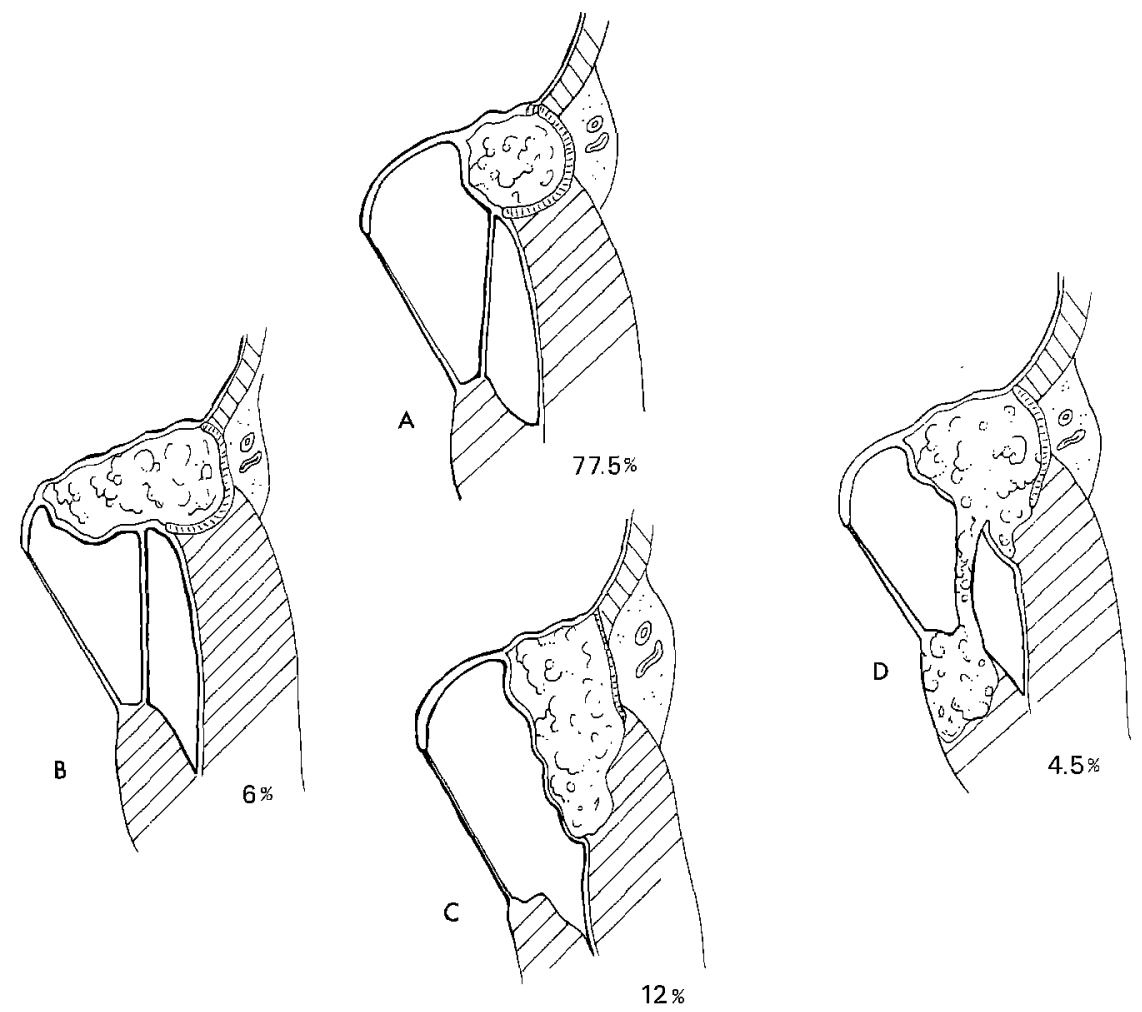

Fig. 2. Ventricular and leaflet extension of the calcification.

Table III. Mitral valve lesions

\begin{tabular}{lcc}
\hline & No. & $\%$ \\
\hline Anulus calcification & 68 & 100 \\
Chordal elongation & 36 & 52.9 \\
Chordal rupture of posterior leaflet & 26 & 38.2 \\
Chordal rupture of anterior leaflet & 10 & 14.7 \\
Papillary muscle elongation & 2 & 2.9 \\
Papillary muscle calcification & 8 & 11.7 \\
Leaflet thickening & 4 & 5.8 \\
Chordal fusion & 1 & 1.4 \\
\hline
\end{tabular}

myocardium by the pledgets will not cause myocardial ischemia.

Exerting traction on these sutures reduces the size of the anulus and closes the AV groove without injury to the circumflex vessels. The closure of the AV groove is facilitated by downward displacement of the atrial edge toward the ventricular edge with a forceps. By means of this technique, the circumflex vessels and surrounding fat are displaced outward and the AV junction is restored as a firm fibrous structure available for valve repair or replacement.

THE "SLIDING ATRIUM TECHNIQUE" IN MYOCARDIAL EXTENSION. Whenever calcium extends to the ventricular myocardium (Fig. 6), the en bloc removal of the calcium barleaves a large area of muscular fibers not covered by fibrous tissue. In such a case the atrial edge is dissected

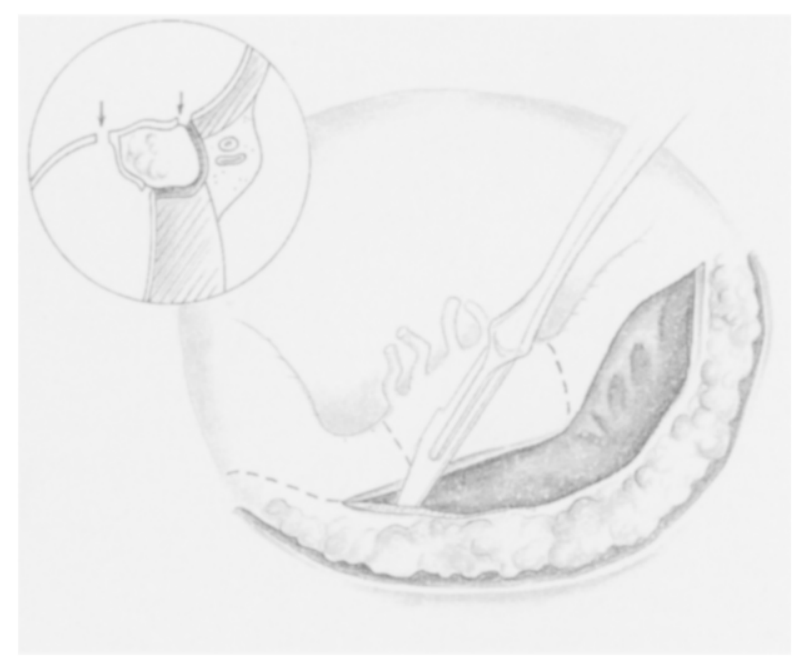

Fig. 3. Decalcification is begun by incising the atrium around the borders of the calcium bar. Then the mural leaflet is detached and retracted, giving access to the ventricular aspect of the calcium formation.

free to mobilize an atrial flap, which is used to cover the decalcified area (Fig. 7). The fat and connective tissue surrounding the circumflex vessels are left attached to the ventricular side. Vertical incisions at the limits of the flap 


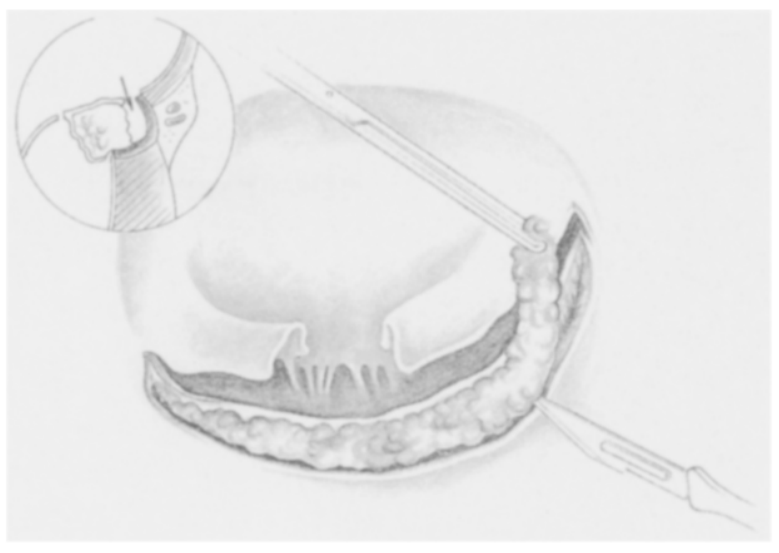

Fig. 4. En bloc resection of the calcium formation. Note the fibrous sheath encapsulating calcium.

are not necessary. Figure-of-eight $2-0$ braided sutures are used as described earlier, with large vertical ventricular bites, taking advantage of any fibrous tissue covering the ventricular endothelium. While gentle traction is being applied to the sutures, the atrial flap is displaced downward with a forceps to cover the area of exposed muscular tissue (Fig. 8). The covering of the muscular surface is further secured by suturing the leaflet remnants to the AV junction, as will be described later. One must understand that the strength of the reconstruction is based on the multiple sutures used to approximate (and not squeeze) living tissues, thus favoring an early and strong healing process. It is therefore critical that all the sutures be tied very gently.

REPAIR IN PAPILLARY MUSCLE CALCIFICATION. The head of one or several papillary muscles may be calcified, raising the problem of proper surgical management. Usually, the calcification also involves the basal and intermediary chords attached to the calcified papillary muscle. Whenever marginal chords with their attachment cuffs are intact, they can be reattached to an adjacent noncalcified papillary muscle. Whenever no marginal chords or papillary muscle heads are available, a chordal transfer after resection of all calcified chords and papillary muscle should be carried out. Valve replacement may be necessary, however, in cases of extensive calcification of one main papillary muscle.

Valve repair. Valve repair is carried out by means of the Carpentier techniques of valvuloplasty ${ }^{4}$ in the following sequential manner: (1) The anterior leaflet prolapse is repaired by chordal transfer or shortening; (2) the posterior leaflet prolapse is repaired by quadrangular resection or chordal shortening (Table IV); (3) the posterior leaflet remnants are sutured to the reconstructed anulus by means of the sliding leaflet technique (Fig. 9); and (4) a prosthetic ring is inserted with the use of the figure-ofeight sutures previously brought out on the atrial side for this purpose (Figs. 10 and 11). These sutures must be tied with gentle traction on both ends to get appropriate tension of the intermediate loops.

Valve replacement. If a valve repair cannot be successfully achieved after decalcification, a valve replacement

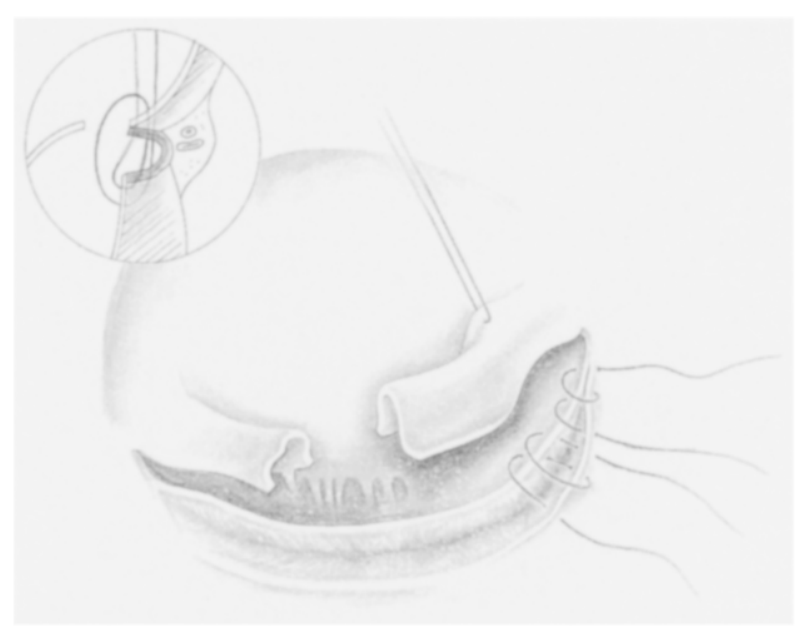

Fig. 5. Reconstruction of the AV junction by figure-ofeight 2-0 vertical sutures. No pledgets are used, so that compression and subsequent ischemia of the myocardium can be avoided.

can be done by means of the following double-layer suture technique. The first row (inner) is a series of $2-0$ horizontal mattress sutures passed through the edges of the reconstructed anulus and then through the inner portion of the sewing ring. The second row (outer) consists of the figure-of-eight sutures used to reconstruct the anulus and brought out through the atrial edge. These sutures are passed through the outer portion of the sewing ring.

Associated surgical procedures and operative parameters. The following associated procedures were necessary in 10 patients $(16 \%)$ : coronary artery bypass in four $(6.5 \%)$, aortic valve replacement in two $(3.2 \%)$, tricuspid valve annuloplasty in four $(6.5 \%)$, and the Cox procedure in one (1.6\%).

The mean cardiopulmonary bypass time was $116 \pm 43$ minutes and the mean crossclamp time was $78 \pm 37$ minutes. Cardiopulmonary bypass was terminated without any pharmacologic support in 46 patients $(75.4 \%)$. Intraaortic balloon counterpulsation was used in two patients $(3.3 \%)$.

Subcutaneous heparin was begun 6 hours after the operation in all patients and was continued for 5 days, followed by oral anticoagulation with warfarin sodium (Coumadin) for 2 months to allow an adequate healing process and incorporation of the prosthetic ring.

\section{Results}

Method of follow-up. Follow-up was obtained through hospital consultations, computerized questionnaires, and telephone calls to patients and referring cardiologists. All patients were followed up for a mean duration of 40 months for a total of 199 patient-years. Continuous variables were presented as mean \pm standard deviation. Long-term survival was calculated according to the actuarial method 


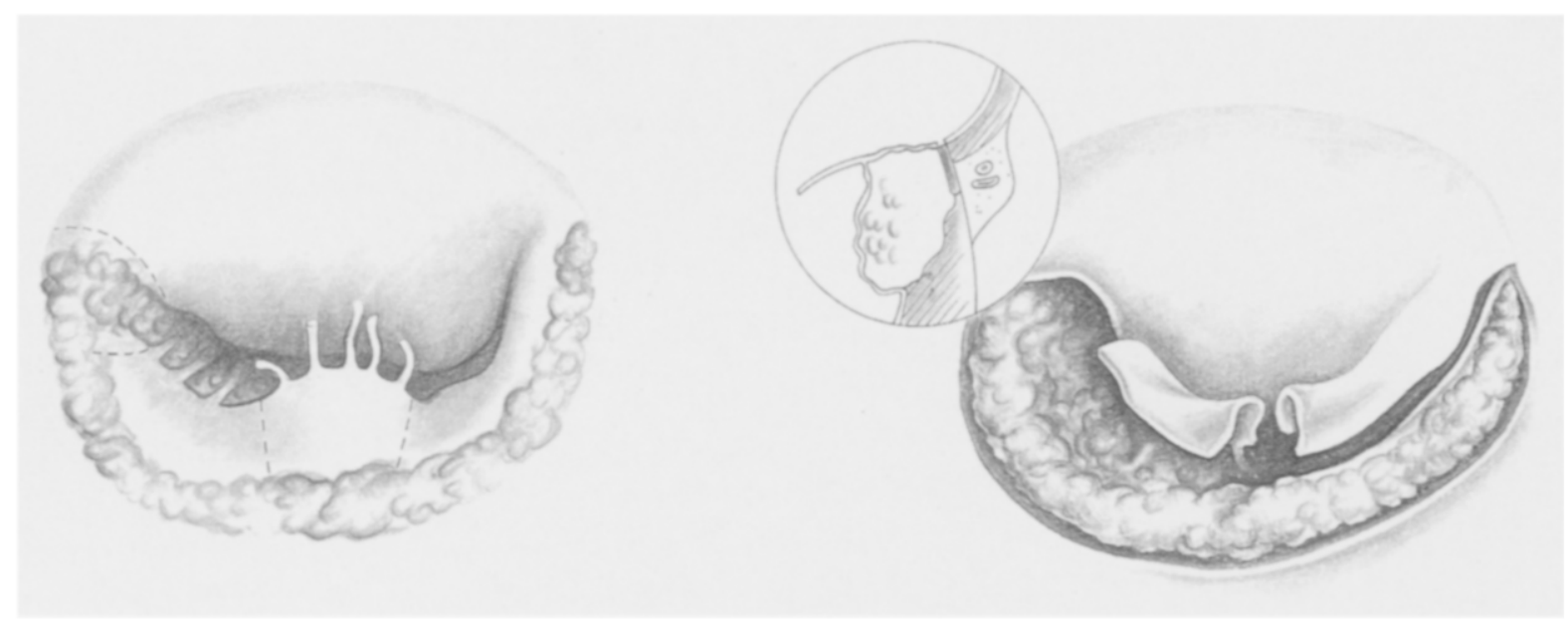

Fig. 6. Extension to the ventricular myocardium requires a more extensive decalcification leaving dissected muscular fibers.

Fig. 7. The sliding atrium technique used after extensive decalcification of the myocardium. The left atrium is dissected free from the AV junction to form an atrial flap.

and actuarial probability estimates with a confidence interval of $95 \%$. The statistical analysis was performed with standard actuarial and linearized statistical techniques used to study long-term survival and valve-related complications. This study followed the guidelines for reporting morbidity and mortality after cardiac valvular operations. ${ }^{5}$

Operative mortality and morbidity. In the group of 67 patients with valve repair, the in-hospital mortality rate was $3.3 \%(n=2)$. Deaths were due to mesenteric infarction in one patient and multiple organ dysfunction in the other. Postoperative complications included "perioperative myocardial infarction" in three patients $(4.9 \%)$, low cardiac output syndrome in eight $(13.1 \%)$, mediastinal bleeding in two $(3.3 \%)$, infection in three $(4.9 \%)$, and chronic complete $\mathrm{AV}$

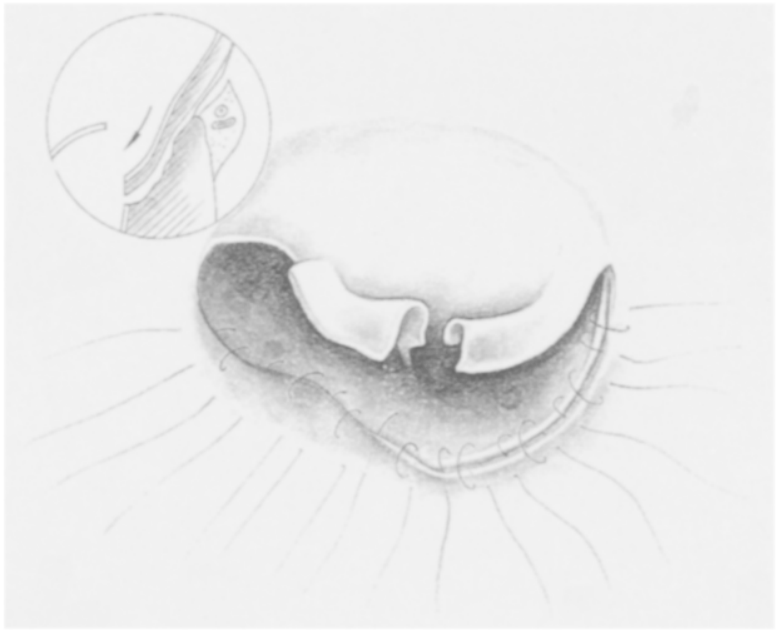

Fig. 8. The atrial flap is used to cover exposed muscular tissue.

block in one (3.3\%). The diagnosis of "perioperative myocardial infarction" was based on creatine kinase MB elevation and ST segment changes (posterior, two cases; anterior, one case). These changes were transitory, and all three patients left the hospital with a normal electrocardiogram. The term low cardiac output refers to cardiac index less than $2.5 \mathrm{~L} / \mathrm{min}$ per square meter or the need for intravenous dobutamine in a dosage of more than $7 \mathrm{gm} / \mathrm{kg}$ per minute for more than 12 hours after the operation. All eight patients with low cardiac output syndrome recovered after a few days.

Late survival. There were two late deaths, accounting for a linearized rate of $1.0 \% / \mathrm{pt}$-yr. The causes of death were acute pulmonary edema in one 


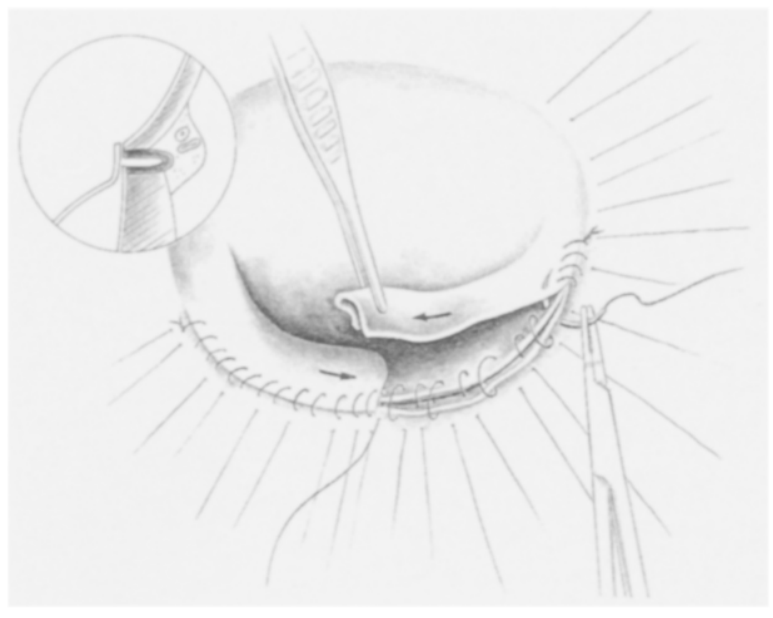

Fig. 9. With the use of the sliding leaflet technique, leaflet remnants are sutured to the reconstructed anulus, thus reinforcing this reconstruction.

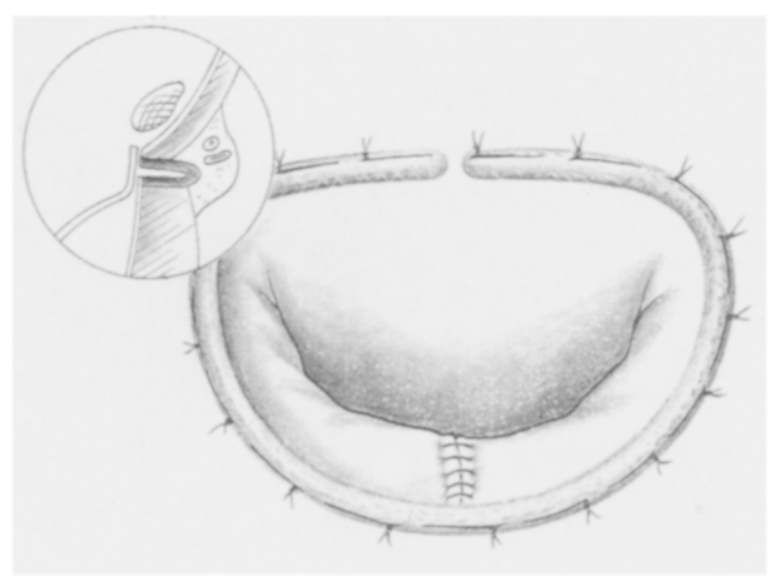

Fig. 10. A prosthetic ring is used to reinforce the anulus reconstruction and valve repair.

patient and sudden death in the other. No autopsy was available. The actuarial survival rate up to 7 years was $93.1 \% \% \pm 7.5 \%$ (Fig. 12).

Valve-related complications. Freedom from valverelated thromboembolism at 5 years was $95.7 \% \pm$ $6.1 \%$, with a linearized rate of $1.0 \% / \mathrm{pt}$-yr. Neither of the two patients having a thromboembolic event died or had chronic neurologic sequelae. At the most recent evaluation, $79.7 \%$ of the patients were not receiving any anticoagulants, and 12 patients (20.3\%) were receiving oral anticoagulants for chronic atrial fibrillation or because of a mechanical aortic valve $(n=1)$. Freedom from anticoagulant-related hemorrhage was $100 \%$ at 9 years.

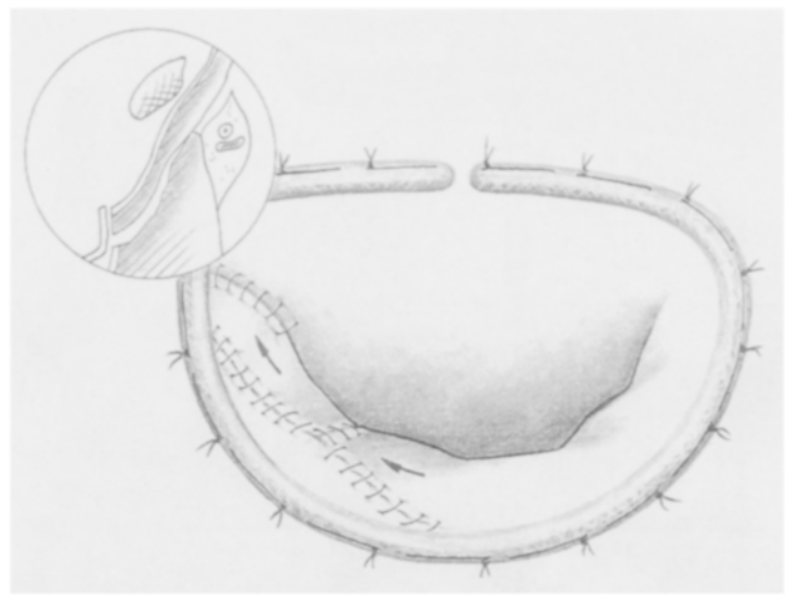

Fig. 11. The sliding atrium technique after ring implantation.

Table IV. Reconstructive technique

\begin{tabular}{lrr}
\hline & No. & $\%$ \\
\hline Ring annuloplasty & 67 & 100 \\
Leaflet & & \\
$\quad$ Posterior resection + sliding & 60 & 89.5 \\
$\quad$ Anterior resection & 3 & 4.4 \\
Chordae & 32 & 47.7 \\
$\quad$ Shortening & 3 & 4.4 \\
$\quad$ Transposition & & \\
Papillary muscle & 17 & 25.3 \\
$\quad$ Shortening or partial resection & 2 & 2.9 \\
$\quad$ Transposition & \\
\hline
\end{tabular}

Reoperations for valve-related causes were performed in four patients, $6,17,62$, and 9 months after the first operation, for recurrent mitral valve prolapse caused by chordal rupture $(n=2)$, bacterial endocarditis $(n=1)$, and hemolysis resulting from prosthetic ring disinsertion $(n=1)$. Three patients required a mitral valve replacement. The remaining patient, with the ring disinsertion, benefited from another repair consisting of prosthetic ring reinsertion. All the patients survived the second operation. Freedom from reoperation for mitral insufficiency at 9 years was $87.1 \% \pm 16.7 \%$ (Fig. 13).

In summary, a total of seven patients had a valve-related complication, and in this group two patients had more than one event. The actuarial rate for freedom from all valve-related complications at 9 years was $85.1 \% \pm 10.6 \%$, for a linearized rate of $3.5 \%$ pt-yr (Fig. 14).

Late results. Among the 60 patients with their native valve at the most recent follow-up, 47 


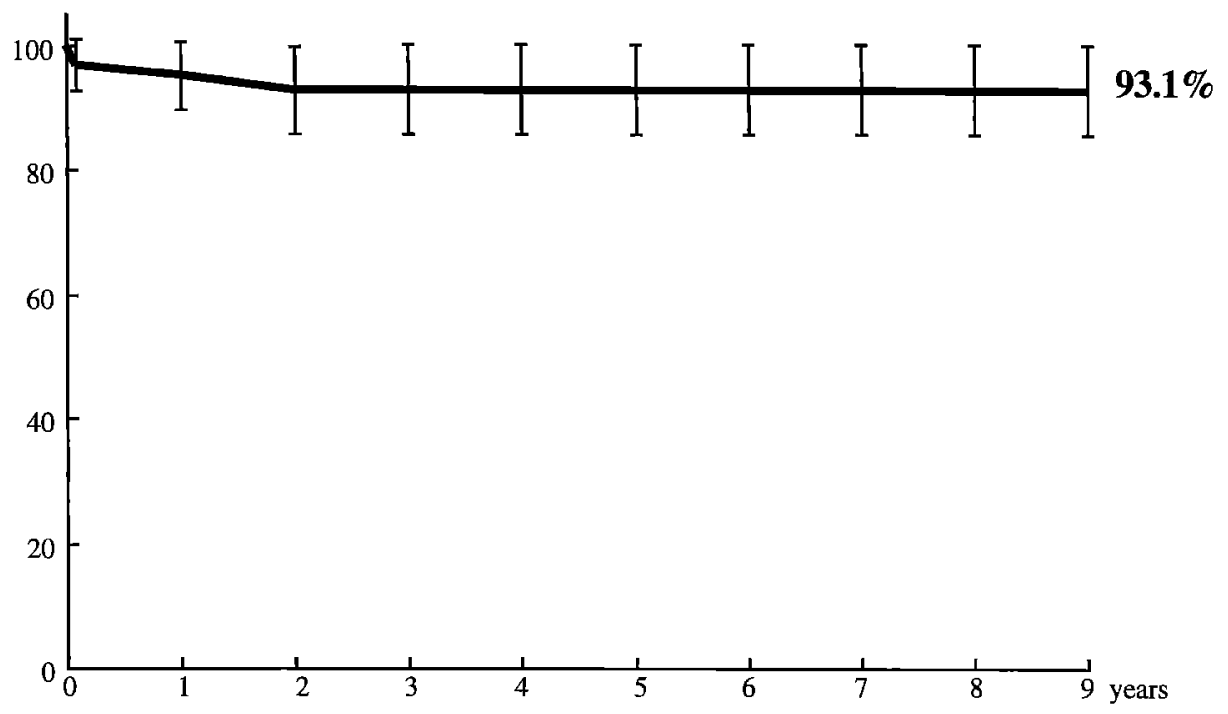

Fig. 12. Actuarial survival in 67 patients with valve repair.

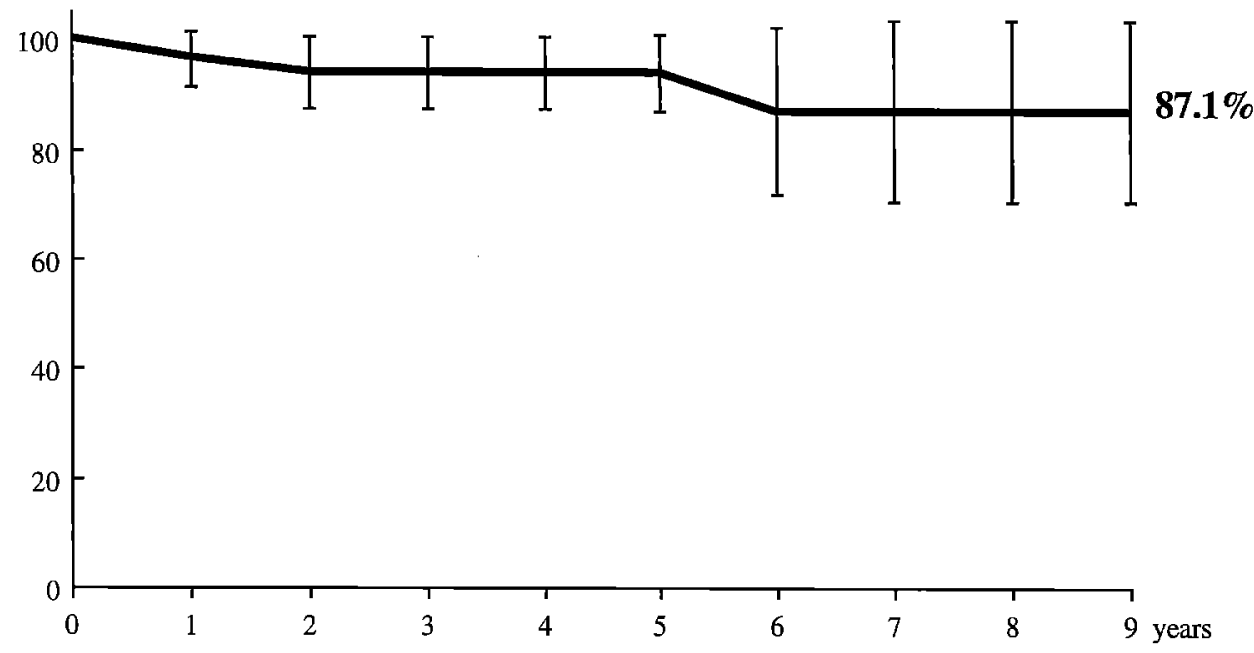

Fig. 13. Actuarial freedom from reoperation.

(78.3\%) were in New York Heart Association class I, $12(20.2 \%)$ were in class II, and one $(1.8 \%)$ was in class III. Sinus rhythm was present in 50 patients $(83.3 \%)$.

All patients underwent recent Doppler echocardiography for this study (Table V). The mean left ventricular end-diastolic and end-systolic diameters were, respectively, $53.5 \pm 4.9 \mathrm{~mm}$ and $36.5 \pm 5.1$ $\mathrm{mm}$. All patients had normal left ventricular function as defined by a shortening fraction greater than $27 \%$. Discrete 1+ (Doppler) leak was documented in 20 patients. Clinically significant valvular leak $(2+)$ was present in five patients.

\section{Discussion}

Extensive calcification of the mitral anulus is seen in elderly persons and in patients with valvular disease. In a reported series of 3334 autopsies, the prevalence of annular calcification was found to be $8.5 \% .^{6}$ In patients older than 90 years of age, the prevalence was $45 \%$ in women and $18 \%$ in men. A systematic echocardiographic study in 5694 patients showed an incidence of anulus calcification of $2.8 \%{ }^{7}$ Female/male sex ratio was 3:2.

There are factors predisposing to annular calcification. In young adults the billowing mitral valve (Barlow's disease) is the most frequent cause, 


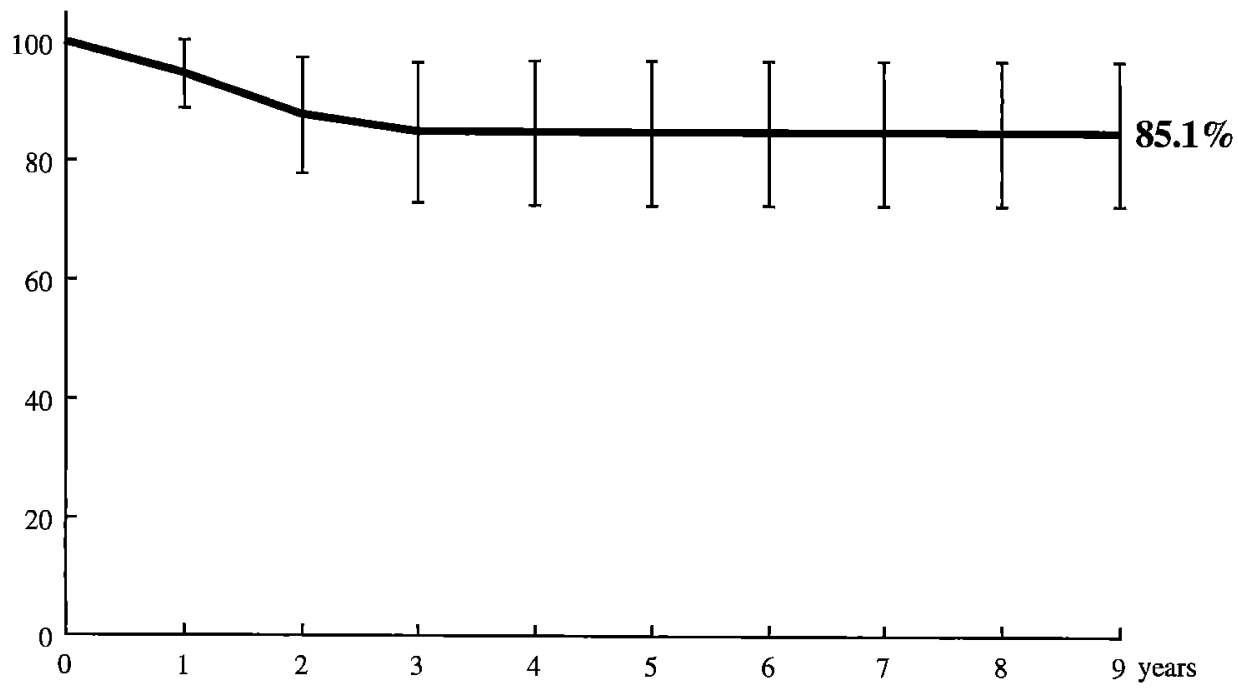

Fig. 14. Actuarial freedom from all valve-related complications.

Table V. Echo-Doppler study

\begin{tabular}{|c|c|c|c|c|}
\hline \multirow[b]{2}{*}{ Echography } & \multicolumn{2}{|c|}{ Preop. $(n=67)$} & \multicolumn{2}{|c|}{ Postop. $(n=60)$} \\
\hline & No. & $\%$ & No. & $\%$ \\
\hline \multicolumn{5}{|l|}{ Mitral insufficiency } \\
\hline $0+$ & 0 & & 32 & 53.3 \\
\hline $1+$ & 0 & & 22 & 36.6 \\
\hline $2+$ & 9 & 12.4 & 5 & 8.3 \\
\hline $3+$ & 39 & 58.2 & 1 & 1.6 \\
\hline $4+$ & 19 & 28.4 & 0 & \\
\hline \multicolumn{5}{|l|}{ Left atrial diameter } \\
\hline Normal $\leq 40 \mathrm{~mm}$ & 10 & 14.9 & 31 & 51.6 \\
\hline Enlarged $>40 \mathrm{~mm}$ & 57 & 85.1 & 29 & 48.3 \\
\hline Mean $(\mathrm{mm})$ & & $52 \pm 10.8$ & & $42.2 \pm 9.5$ \\
\hline \multicolumn{5}{|c|}{$\begin{array}{l}\text { Left ventricular } \\
\text { end-diastolic diameter }\end{array}$} \\
\hline Normal $\leq 55 \mathrm{~mm}$ & 7 & 10.5 & 49 & 81.6 \\
\hline Enlarged $>55 \mathrm{~mm}$ & 60 & 89.5 & 11 & 18.3 \\
\hline Mean $(\mathrm{mm})$ & & $63 \pm 6$ & & $53.5 \pm 4.9$ \\
\hline \multicolumn{5}{|l|}{$\begin{array}{l}\text { Left ventricular systolic } \\
\text { diameter }\end{array}$} \\
\hline Normal $\leq 40 \mathrm{~mm}$ & 33 & 49.3 & 53 & 88.3 \\
\hline Enlarged $>40 \mathrm{~mm}$ & 34 & 50.7 & 7 & 11.6 \\
\hline Mean $(\mathrm{mm})$ & & $40 \pm 6$ & & $36.5 \pm 5.1$ \\
\hline \multicolumn{5}{|l|}{ Shortening fraction } \\
\hline Normal $\geq 27 \%$ & 57 & 85.1 & 53 & 88.3 \\
\hline Altered $<27 \%$ & 10 & 14.9 & 7 & 11.6 \\
\hline Mean & & $37 \pm 10$ & & $35 \pm 6$ \\
\hline
\end{tabular}

whereas in elderly persons fibroelastic deficiency is predominant. The latter pathologic entity, first described by one of us, ${ }^{1}$ was defined as follows:

- Clinically by the recent onset of mitral valve insufficiency in an elderly patient (average age at operation 61 years)
- Anatomically by an almost normal configuration of the mitral valve with the exception of the prolapsed area, which displays tissue proliferation and thickening while the remaining tissue and chordae are thinner and more transparent than normal

- Histochemically by collagen, elastin, and proteoglycan deficiency with a well-preserved three-layer architecture of the leaflet tissue

These features contrast with those of Barlow's disease, which is characterized as follows ${ }^{1,8}$ :

- Clinically by a long-lasting evolution of mitral valve disease (e.g., click syndrome, systolic murmur) and by a younger age at operation (average age 48 years)

- Macroscopically by a billowing valve with excess tissue, myxoid appearance, and chordal thickening

- Microscopically by extensive myxoid degeneration with destruction of the architecture of the leaflet tissue and myxoid covering of the chordae tendineae

Other connective tissue disorders (Marfan and Hurler syndromes ${ }^{9,10}$ ) have been associated with annular calcification. Valve insufficiency in these cases is due to the valvular disease rather than to the calcification. Annular calcification, however, can be seen in patients without any primary valve tissue disorders but with systemic hypertension or metabolic diseases (diabetes and hypercalcemia). ${ }^{11,12}$ 


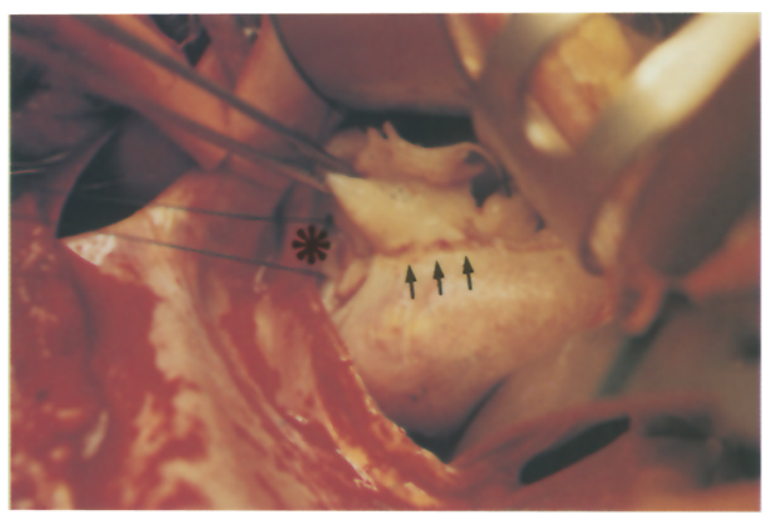

Fig. 15. Early phases of calcification (arrows) are studied beyond the limits of mature calcification (star).

Calcium infiltration of the base of the posterior leaflet reduces leaflet mobility, increases traction on the chordae, elevates the leaflets, and thus facilitates chordal elongation or rupture, a cause of secondary mitral valve insufficiency. More rarely, deposition of calcium also induces some degree of mitral valve stenosis.

The pathophysiology of mitral anulus calcification is a subject of controversy. The most common hypothesis is progressive degeneration of the anulus throughout life, ${ }^{13}$ with thickening and disorientation of collagen fibers, decrease in mucopolysaccharides, and progressive accumulation of fatty tissue. However, in the great majority of the cases $(93 \%$ in this series), the calcification is due to a preexisting valvular disease, usually a degenerative valvular decrease with leaflet billowing, leaflet prolapse, and excess tissue.

In all our cases, a careful examination of the mitral anulus beyond the limits of the calcification allowed recognition of the early phases of calcium formation and speculation on the mechanisms involved (Fig. 15): many radial fissures and zones of dehiscence were present at the attachment of the mural leaflet, exposing the underlying annular tissue. These defects were filled with lipoid substances, protein deposits, and platelet aggregates. The closer to the calcified process these deposits were, the more organized they were, with spots of early mineralization. In front of these areas, as well as in areas of mature calcification, there was excess tissue, billowing leaflet, or leaflet prolapse. The numerous radial fissures, tears, or dehiscences at the attachment of the leaflets to the anulus were obviously the result of excess tension resulting from excess tissue according to Laplace's law (Fig. 16). Besides these

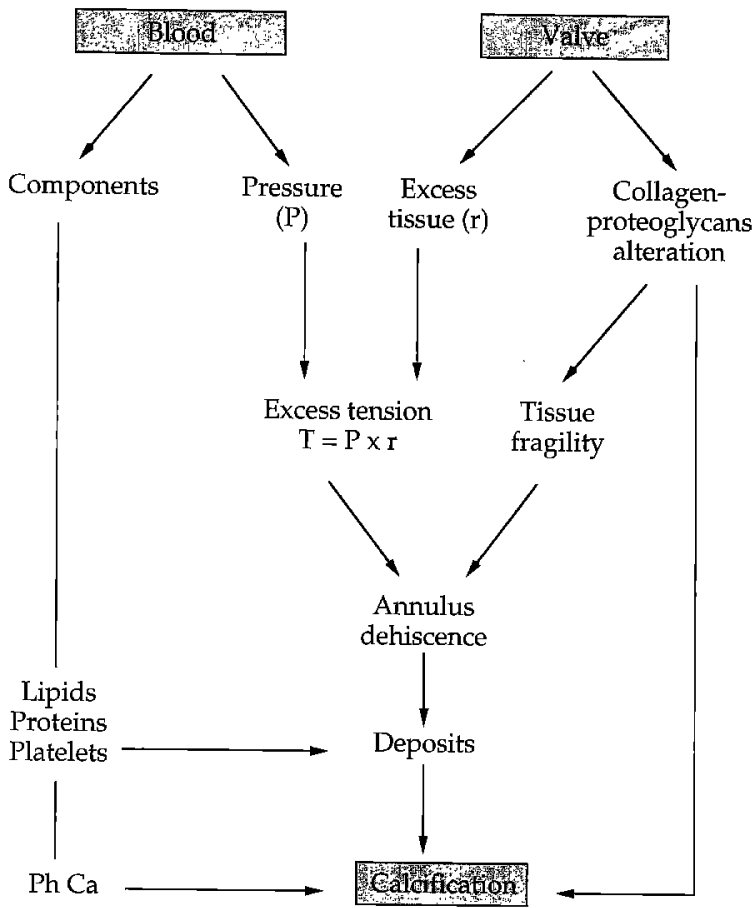

Fig. 16. Proposed mechanism of mitral valve anulus calcification. Mechanical factors play a role through excess blood pressure and excess tension on the leaflets. Chemical factors play a role through collagen and proteoglycans alteration and blood components infiltration.

mechanical factors, biochemical factors also played a role. Histochemical studies have shown that proteoglycans and collagen are severely altered in degenerative valvular disease. ${ }^{1,13}$ A vicious cycle was thus initiated leading from a valvular degenerative process with collagen denaturation to excess tissue, excess leaflet tension, and increased fragility. This led finally to anulus dehiscence and ischemia with lipid, protein, blood cells, and calcium phosphate deposition (Fig. 16). This proposed mechanism of calcification of the anulus fibrosus has been confirmed experimentally in our laboratory. In juvenile sheep the posterior leaflet was enlarged with a diamond-shaped patch of glutaraldehyde-preserved autologous pericardium, and the anulus was perforated in multiple points, exposing the annular tissue to blood. Fifteen months later, the anulus fibrosus corresponding to the enlarged leaflet showed areas of dehiscence and calcification, whereas the leaflet tissue and the pericardial patch were not calcified.

The operation remains a challenge for the surgeon. Several techniques of valve replacement have been published, with mixed results. ${ }^{14,15}$ Ventricular 
rupture is more frequent after valve replacement in patients with annular calcification. Experimental and clinical studies have underlined the role of the subvalvular apparatus in left ventricular contraction. $^{16-21}$ Indeed, the correction of severe mitral valve insufficiency increases left ventricular afterload, but left ventricular function is improved over the long term when the native valve is preserved, as shown by the excellent long-term clinical outcome of patients who underwent mitral valve reconstructive with Carpentier's techniques. ${ }^{22-25}$ Anulus reconstruction in extensive mitral anulus calcification was introduced clinically in 1986 by one of us. ${ }^{26}$ En bloc excision of the calcium deposit and subsequent anulus reconstruction was shown to be not only possible but also reproducible. ${ }^{27}$ Contrary to expectation, it was found safer and easier to completely decalcify the anulus and reconstruct the mitral valve than to try to implant a prosthesis with sutures passed through the calcified anulus. Others, however, have reported excellent results with decalcification limited to the area of leaflet resection and repair. ${ }^{27}$ Reconstruction of the anulus fibrosus after decalcification was carried out with non-pledgetsupported figure-of-eight sutures. As opposed to pledget-supported sutures, which produce localized myocardial ischemia, the figure-of-eight vertical sutures preserve the vascularization of the myocardium and therefore facilitate a faster and stronger healing of the anulus. In three cases of this series in which a valve replacement was necessary because of a recurrent valve insufficiency, the reconstructed new anulus was found to be fibrotic and strong and was holding the sutures quite well.

The clinical results in this series have been gratifying. The operative mortality compares favorably with that of valve replacement, whether associated with anulus calcification or not. Even though patients with extensive mitral annular calcification represent an elderly group, in which surgical complications are expected to be more frequent, ${ }^{25}$ the mortality and morbidity were low in this series. No myocardial infarctions resulted from lesions of the circumflex artery, and there was no case of left ventricular rupture or anulus dehiscence after the repair (the three "perioperative myocardial infarctions" seen in this series were located anteriorly $[n=1]$ or posteriorly $[n=2]$ but not laterally). At least two reasons can explain these good results: (1) the removal of all abnormal tissue facilitates a good healing process and (2) the strength of the repair results from the three-tiered reconstruction-fig- ure-of-eight sutures, leaflet remnant fixation to the reconstructed anulus, and prosthetic ring reinforcement. The long-term survival in this series is similar to that of other series of mitral valve reconstructions in which the same techniques were used. ${ }^{22-25}$ The linearized rate of valve-related complications (i.e., thromboembolism and hemorrhagic events) was lower than those of other reported series of mitral valve replacement. Endocarditis rate was comparable with that of recent valve replacement series. Freedom from valve-related reoperation at 5 years was similar to those of our previous reports of reconstructive mitral valve surgery in patients with noncalcified mitral valve disease. ${ }^{22-25}$

In conclusion, this study shows that extensive calcification of the mitral valve anulus does not preclude the use of reconstructive techniques because, in the majority of the cases, the process of calcification does not involve the other components of the mitral valve apparatus. En bloc decalcification, anulus reconstruction, and valve repair by means of the Carpentier techniques provide good and stable long-term results in this particularly difficult group of patients.

\section{REFERENCES}

1. Carpentier A, Chauvaud S, Fabiani JN, et al. Reconstructive surgery of mitral valve incompetence: ten-year appraisal. J Thorac Cardiovasc Surg 1980;79:338-48.

2. Carpentier A. The "reference point." Le Club Mitrale Newsletter 1989;I:6.

3. Carpentier AF, Lessana A, Relland JYM, et al. The "PhysioRing": an advanced concept in mitral valve annuloplasty. Ann Thorac Surg 1995;60:1177-86.

4. Carpentier A. Cardiac valve surgery-the "French correction." J Thorac Cardiovasc SuRg 1983;86;323-37.

5. Edmunds L, Clark R, Cohn L, Miller D, Weisel R. Guidelines for reporting morbidity and mortality after cardiac valvular operations. J ThoraC CARdIOvasC SuRg 1988;96: 351-3.

6. Pomerance A. Pathological and clinical study of calcification of the mitral valve ring. J Clin Pathol 1970;23:354-61.

7. Savage D, Garnison R, Castelli W, et al. Prevalence of submitral calcium and its correlation in the general population-base sample (the Framingham study). Am J Cardiol 1983;51:1375-8.

8. Boudoulas H, Kolibash A, King P, Wooley C. Mitral valve prolapse and the mitral valve prolapse: a diagnostic classification and pathogenesis of syndrome. Am Heart J 1989;118: 797-815.

9. Grossman M, Knott A, Jacoby W. Calcified annulus fibrosus with mitral insufficiency in the Marfan's syndrome. Arch Intern Med 1968;121:561-3.

10. Goodman H, Dorney E. Marfan's syndrome with massive calcification of the mitral annulus at age twenty-six. Am J Cardiol 1969;24:426-31.

11. Aronow WS, Schwartz KS, Koenigsberg M. Correlation of 
serum lipids, calcium and phosphorus, diabetes mellitus, aortic valve stenosis and history of systemic hypertension with presence or absence of mitral annular calcium in persons older than 62 years in a long term health care facility. Am J Cardiol 1987;59:381-2.

12. Nair CK, Sudhakaran C, Aronow WS, Thomson W, Woodruff MP, Sketch MH. Clinical characteristics of patients younger than 60 years with mitral annular calcium: comparison with age and sex matched control subjects. Am J Cardiol 1984;54:1286-7.

13. Roberts W, Perloff J. Mitral valvular disease: a clinicopathologic survey of the conditions causing the mitral valve to function abnormally. Ann Intern Med 1972;77:939-75.

14. Danielson GK, Cooper E, Ifuku M. Severence of mitral prosthesis fixation sutures by annulus calcification. J THORAC Cardiovasc Surg 1967;53:858-65.

15. Coselli JS, Crawford ES. Calcified mitral valve annulus: prosthesis insertion. Ann Thorac Surg 1990;49:964-9.

16. Crawford MJ, Souchek J, Oprian CA, et al. Determinants of survival and left ventricular performance after mitral valve replacement. Circulation 1990;81:1173-81.

17. David TE, Unden DE, Strauss HD. The importance of the mitral apparatus in left ventricular function after correction of mitral regurgitation. Circulation 1983;68(Suppl):II76-82.

18. Goldman ME, Mora S, Guarino T, Foster V, Mindich B. Mitral valvuloplasty is superior to valve replacement for preservation of left ventricular function: an intraoperative two-dimensional echocardiographic study. J Am Coll Cardiol 1987; 10:568-75.

19. Hansen DE, Cahill PD, De Campli WM, et al. Valvularventricular interaction: importance of the mitral apparatus in canine left ventricular systolic performance. Circulation $1986 ; 73: 1310-20$

20. Hansen DE, Cahill PD, Derby GC, Miller DC. Relative contributions of the anterior and posterior mitral chordae tendineae to canine global left ventricular systolic function. J Thorac Cardiovasc Surg 1987;93:45-55.

21. Yun KL, Fann JI, Raghill SC, et al. Importance of the mitral subvalvular apparatus for left ventricular segmental systolic mechanics. Circulation 1990;82(Suppl):IV88-104.

22. Deloche A, Jebara VA, Relland JYM, et al.. Valve repair with Carpentier techniques: the second decade. J THORAC Cardiovasc Surg 1990;99:990-1002.

23. Spencer FC, Colvin SB, Culliford AT, Isom OW. Experiences with the Carpentier techniques of mitral valve reconstruction in 103 patients (1980-1985). J Thorac Cardivasc Surg 1985; 85:341-50.

24. Cosgrove DM, Chavez AM, Lytle BW, et al. Results of mitral valve reconstruction. Circulation 1986;74(Suppl):I82-7.

25. Jebara VA, Dervanian $P$, Acar $C$, et al. Mitral valve repair using Carpentier techniques in patients more than 70 years old: early and late results. Circulation 1992;86(Suppl):II53-9.

26. Carpentier A. Mitral valve repair in calcified mitral valve annulus. Le Club Mitrale Newsletter 1989;1:6-8.

27. Grossi AG, Galloway AC, Steinberg BM, et al. Severe calcification does not affect long-term outcome of mitral valve repair. Ann Thorac Surg 1994;58:685-8.

\section{Discussion}

Dr. Tirone E. David (Toronto, Ontario, Canada). I have approached this problem differently, obtaining similar results.
Instead of mobilizing the left atrium and bringing it over the ventricle, we detach the leaflet the way Dr. Carpentier described, remove all the calcified material. and then take a strip of autologous pericardium and sew it to the endocardium of the left ventricle with running 4-0 Prolene suture (Ethicon, Inc., Somerville, N.J.) from commissure to commissure. The leaflet is then reattached to the pericardium and an annuloplasty ring is reimplanted to reinforce the repair. The reason we do it this way is that early on in our experience we had a case of AV separation. I would like to hear Dr. Carpentier's comments on separation of the AV groove after decalcification of the mitral anulus.

Dr. Carpentier. We have also been using the technique of pericardial reinforcement of the anulus with good results. However, at least in our hands, the technique I just described has yielded superior results. I attribute the difference in results to the use of living vascularized tissue, which provides faster and stronger healing. The atrial flap is marvelous material once you have the courage to mobilize it.

Dr. Lawrence I. Bonchek (Lancaster, Pa.). Professor Carpentier has demonstrated once again that true surgical pioneers advance boldly and decisively where others hesitate to proceed. I suspect that most cardiac surgeons, myself included, prefer to avoid extensive débridement of calcium from the mitral anulus for fear of encountering the outside world behind the heart. I think Donald Ross has called this the fresh air behind the heart. Indeed it is usually possible to devise some method for mitral repair or replacement in the presence of a calcified anulus without the extensive débridement described by Professor Carpentier. In the case of ruptured chords to the posterior leaflet with a flail segment, even in the presence of annular calcification, I find it is possible in many patients to use the techniques described by Professor Carpentier for quadrangular resection and sliding repair. However, in these patients the anulus is not plicated posteriorly because the calcified posterior anulus is not dilated. If necessary, plication can sometimes be done at one of the commissures, or a ring may be inserted with sutures at the base of the leaflets, but these sutures stabilize and do not reduce the size of the anulus. What is the advantage of decalcification in those types of patients?

I have several other questions. Can you tell us, Professor Carpentier, more specifically what criteria are used to select patients for this procedure and what criteria, if any, are used to exclude them? Were all calcified mitral anuli seen during this time frame débrided in this extensive manner? If not, what other methods were used to deal with calcified anuli and were those other methods successful? How often was valve replacement necessary as a primary procedure, if at all?

Last, I would like to ask a few technical questions. Does the Physio ring (Baxter Healthcare Corporation, Edwards Div., Irvine, Calif.) offer specific advantages in these cases, or would a totally flexible ring have specific application in these patients to avoid ring dehiscence? When valve replacement is necessary, exactly what suture techniques do you use?

Certainly the increasing experience with the Cox maze procedure has provided surgeons greater familiarity with the anatomic relationships in this area, but I suspect that it will be a while before such an aggressive approach to 
annular decalcification becomes commonplace. Nevertheless, Professor Carpentier has provided encouragement that these problems can be attacked aggressively.

Dr. Carpentier. The advantage of decalcification is that it brings to the patient a higher quality of long-term results and a safer operation. Of course it took me some time to develop and to have the courage to do this operation. It is not as hazardous and as difficult as you think. It is, of course, preferable to decalcify. You do the same every day when you decalcify an aortic valve. Everybody knows that it is better to have a decalcified aortic valve for a long-term, lasting result rather than to leave some calcium. This is the rationale.

Regarding the criteria for inclusion or exclusion, in my personal experience, in the same time frame, I have used it in only a single case of valve replacement. The patient was a very elderly woman who had extensive calcification. I tried to pass sutures through the calcium bar, and I discovered that this did not lead to fragmentation of this calcium bar. So in this case I used valve replacement. Obviously it is not at all the ideal technique. The aim of the reconstruction is really to cure the patient, ideally for the rest of his or her life.

Regarding the Physio ring versus the rigid ring, I prefer a classic rigid ring in this particular case because I want the anulus to be totally fixed. I do not want to have any motion at this level during the time of the healing process.

Valve replacement has been done in three cases at a later stage and was not difficult at all. It was amazing to see that we had a new anulus, and it was not difficult to get some strong tissue or to find enough thickness to pass the sutures and avoid the circumflex artery.

Dr. Stephen B. Colvin (New York, N.Y.). Sixteen years ago, having recently completed training, I was sent to Paris by Frank Spencer to see if Professor Carpentier's techniques could be imported to New York. Professor Carpentier graciously allowed me to learn his techniques and launched me, my colleagues, and our trainees on our careers in mitral valve reconstruction. At that time I was cautioned that three things precluded successful application of his reconstructive techniques-overly extensive involvement to the mural leaflet, perhaps greater than two thirds; extensive bileaflet involvement with multiple flail segments; and extensive annular calcification. Currently most of these exclusions have fallen by the wayside.

I marvel at the magic that Dr. Carpentier is performing. This is certainly an area of the heart on which to work with the utmost caution. However, the benefits of a reconstructed valve are clear. I still wonder how often it is necessary to perform such an extensive annular extraction. Over a dozen years ago, when presented with a patient with severe mitral insufficiency, pulmonary hypertension, massive annular calcification, and a flail mural leaflet, in whom anticoagulation was contraindicated, I cautiously débrided that portion of the calcium from the anulus and ventricle that was necessary to approximate the anulus and leaflet posteriorly. The patient did well and has continued to do well up until the present time.

Last year Gene Grossi from our group reported on a series of 64 patients who required concomitant calcium débridement. We demonstrated that our technique was feasible, safe, and durable with merely a localized débridement.

Out to 10 years, $92 \%$ of the patients with nonrheumatic disease are free of any problems of insufficiency or reoperation. This is comparable with the results that you have presented.

In exactly which cases do you think there are distinct advantages to performing an extensive extraction versus a localized débridement? What do you see might be advantages of one versus the other specifically for the patient? I have not found fragmentation of calcium to cause embolization when care is taken to remove the particles of calcium that are within the ventricle or the atrium. Also, in a patient with a left dominant coronary circulation, have you had any concern about the fact that distortion, perhaps of the circumflex, might lead to an extensive injury if that were to occur?

Dr. Carpentier. I have nothing against partial resection versus complete resection if you feel more comfortable with it. What is important is to be able to reapproximate the two leaflet remnants without tension. It is sometimes difficult when you have a complete calcification. As I already emphasized, it is a question of personal philosophy. I think the long-term result is probably better if you can do a complete resection. With time you may progressively enlarge your size of resection.

I have never seen any injury of the circumflex artery, nor distortion, most probably because we use a sliding leaflet technique whenever we have a large resection.

Dr. Meredith L. Scott (Orlando, Fla.). At the Florida Heart Institute we have done 516 classic Carpentier repairs and we have done only five in this subset. Most of these get the classic St. Jude Medical repair. I have had some difficulties with this operation. I could not repair many of these valves at the initial operation and had to replace the valves in most instances. I also had to reoperate in one case in 4 months.

As a result of the extensive AV dissection, have there been any AV separations in the postoperative period? And, again, has there been any injury to the circumflex coronary artery requiring bypass? In how many cases did you have to resort to replacement at the initial operation because you could not repair the valve?

Dr. Carpentier. We have not seen any AV separations, and to this moment we have not seen any instances of circumflex artery compression or folding. We were obliged to do only one valve replacement among the 67 patients.

Now, if I can summarize briefly what valve reconstruction is all about, whether to completely or partially decalcify the valve, whether to use partial support or a complete circular ring, I can say this: If you ask an engineer how to repair a building damaged by an earthquake, he will tell you that it is best to reinforce the four sides of the building rather than just one or two, and that a circumferential reinforcement is ten times stronger than a partial one. The same principle applies to a mitral valve. The mitral valve is the damaged building, the ring is the circumferential reinforcement, and the heart, a permanent earthquake! 